\title{
Psicologia e a questão agrária no Brasil: novos desafios para a profissão
}

\section{Psychology and the agrarian question in Brazil: new challenges for the profession}

\author{
Kátya de Brito e Silva (orcid.org/0000-0002-5617-8612) ${ }^{1}$ \\ João Paulo Macedo (orcid.org/0000-0001-6151-3422)²
}

\begin{abstract}
Resumo
A questão agrária diz respeito a um problema social advindo da concentração da estrutura fundiária da terra, a qual é responsável por gerar concentração de riqueza e, dessa forma, desigualdades sociais e regionais. O presente artigo propõe investigar de que maneira a produção de conhecimento brasileira em Psicologia tem abordado o tema da questão agrária em seus estudos, bem como tem contribuído para produzir norteadores para a profissão. Com esse objetivo, foi realizado um estudo bibliográfico na base de dados Scientific Electronic Library Online (SciELO) em janeiro de 2017, sendo encontrados 18 artigos abordando a temática. A análise do material considerou os seguintes eixos: entendimentos da Psicologia acerca da questão agrária e abordagens teóricas, analíticas e práticas da Psicologia a respeito da questão agrária. Espera-se colaborar com o debate acerca da inserção da Psicologia na discussão sobre a questão agrária, contribuindo para a problematização de sua participação no campo das ruralidades.
\end{abstract}

Palavras-chave: Psicologia. Questão agrária. Rural.

\begin{abstract}
The agrarian question concerns a social problem arising from the concentration of the land structure, which is responsible for generating concentration of wealth and, thus, social and regional inequalities. This article proposes to investigate how the production of Brazilian knowledge in Psychology has addressed the theme of the agrarian question in its studies, as well as has contributed to produce guidelines for the profession. With this purpose, a bibliographic study was conducted in the Scientific Electronic Library Online (SciELO) database in January 2017, and 18 articles addressing the theme were found. The analysis of the material considered the following axes: understandings of Psychology about the agrarian question, and theoretical, analytical and practices approaches of Psychology about the agrarian question. It is expected to collaborate with the debate about the insertion of

1 Universidade Federal do Rio Grande do Norte, Natal, Brasil. E-mail: katyabsilv@gmail.com.

2 Universidade Federal do Delta do Parnaíba, Parnaíba, Brasil. E-mail: jpmacedo@ufpi.edu.br.
\end{abstract}


Psychology in the discussion on the agrarian question, contributing to the problematization of its participation in the field of ruralities.

Keywords: Psychology. Agrarian question. Rural.

A aproximação da profissão com o tema da questão agrária nos últimos anos (Lopes, 2007) evidencia o histórico distanciamento da Psicologia com o rural e com a questão social no país (Albuquerque, 2001, 2002; Leite et al., 2013; Yamamoto, 2012). Trata-se de um encontro tardio, se comparado a outras áreas de conhecimento e atuação profissional. No caso de psicólogas/os, esse encontro foi proporcionado, em grande medida, pelas experiências iniciais de extensão universitária na década de 1970 e pela inserção profissional nas políticas sociais a partir dos anos 1980.

É válido destacar que a concepção de rural utilizada neste estudo ultrapassa os sentidos relativos a espaço físico e a atividades agrícolas, sendo considerado como uma categoria de reflexão teórica. Compreende-se rural, para além do que se entende por zona rural, no sentido de abarcar a diversidade de conexões com o urbano, atitudes e imagens que conformam uma ruralidade contemporânea "marcada pela coexistência de diferentes códigos culturais e pela possibilidade de negociação e trânsito entre eles" (Carneiro, 2012, p. 254).

Para Leite et al. (2013), o envolvimento com os contextos rurais exige que a profissão avance mais conectada e comprometida com os povos rurais e suas singularidades. As condições de vida, saúde, Educação e trabalho, além das lutas sociais deflagradas em torno da democratização e do acesso a terra, precisam ganhar espaço na agenda de pesquisa e campo profissional de psicólogas/os. Sendo assim, cabe considerar a diversidade cultural, econômica e regional dos povos rurais para compreender e contribuir com o debate acerca dos processos sociais do campo, os movimentos sociais rurais e as novas ruralidades, assim como sobre as políticas públicas relativas aos meios rurais e desenvolvimento territorial. 
Isso demonstra a necessidade de um novo posicionamento, que supere o ideário individualista e centrado quase que exclusivamente no sujeito psicológico, o qual acabou se configurando como um dos elementos definidores da cultura e da identidade profissional de psicólogas/os (Dimenstein, 2000). Com isso, gerou uma barreira e o distanciamento da profissão ante as demandas e conflitos sociais nas/entre as diferentes classes sociais. Restrita a si mesma e a uma parcela da sociedade, a que podia consumir os seus serviços no meio urbano, a Psicologia acabou desprezando a formação da sociedade brasileira e excluindo e desqualificando os povos do campo e os problemas que dizem respeito a toda a sua territorialidade (Crepop, 2019a).

Para Dantas et al. $(2018$, p. 2),

\begin{abstract}
Isso em parte se deve ao processo de regulamentação e consolidação da Psicologia no Brasil, que ocorreu em um contexto marcado por um projeto de modernização da sociedade, em que algumas necessidades postas pelo processo de instauração do capitalismo tardio são respondidas por conhecimentos psicológicos que hegemonicamente focam sua atenção nas populações urbanas, especialmente naquela parcela com capacidade de vender sua força de trabalho ao capital nascente.
\end{abstract}

De forma mais ampla, não se pode esquecer de que a origem da Psicologia foi marcada por certo etnocentrismo com a imposição de um modelo de ser humano: o homem branco-europeu-cristão, tendo desconsiderado outros contextos e particularidades (Alves \& Delmondez, 2015). Isso ajuda a explicar a situação ainda habitual no contexto acadêmico da América com a manutenção dos colonialismos que tanto negaram a riqueza cultural e a falta de reconhecimento das culturas originárias, milenárias e presentes na América Latina (Góis et al., 2016). De tal forma, fica evidente compreender que temáticas relacionadas ao sistema agrário latino-americano, como a desigualdade, a exclusão, a concentração de terras e 
situações de violências no campo e seus efeitos em indivíduos, grupos e comunidades (Kay, 2002; Zimerman, 2016), acabaram não sendo foco de estudo da Psicologia.

Isso posto, apesar das experiências pioneiras e inovadoras de Helena Antipoff, envolvendo a Psicologia e a Educação rural na década de 1940 (Martins, Augusto \& Antunes-Rocha, 2011), um posicionamento mais crítico da profissão em relação aos povos do campo no Brasil começou a surgir na década de 1970 e 1980, a partir das interlocuções entre Psicologia Social Comunitária e a Educação Popular, somado ainda às articulações com os Movimentos Sociais de Luta pela Terra (Crepop, 2019). Esse contexto foi marcado pela herança de luta e organização deixada pelas Ligas Camponesas, o fortalecimento do debate sobre a Reforma Agrária e o trabalho de alfabetização de Paulo Freire. Registram-se também as contribuições de autores da Psicologia Latino-Americana e das Ciências Sociais, com elaboração de propostas interventivas e de pesquisa, sob a égide da pesquisa ação e participante, que influenciaram fortemente a realização de projetos de extensão em universidades do Sudeste e do Nordeste brasileiro, tanto nas periferias dos grandes centros urbanos quanto em áreas rurais (Campos, 1998; leno Neto et al., 1985; Ximenes \& Góis, 2004).

A partir do fim dos anos 1980, observa-se maior penetrabilidade do tema da questão agrária na Psicologia, com a realização de estudos em nível de pós-graduação envolvendo a temática. Os destaques iniciais foram investigações sobre o Movimento Sem Terra (MST), fundado em 1984 , tema de diversas dissertações e teses $(n=11)$ no período de 1984-2004 (Domingues, 2007). Destaca-se, nesse sentido, que o trabalho mais antigo foi o realizado por Tarelho (1988). Quanto aos estudos sobre Psicologia e povos indígenas, estes seguiram o mesmo ritmo. Apesar de os primeiros estudos terem surgido na década de 1980, a revisão de literatura realizada por Vitale e Grubits (2009), e atualizada por Ferraz e Domingues (2016), indica que foi a partir dos anos 1990 que houve maior interesse sobre o assunto, com crescimento mais significativo da produção nos anos 2000 .

Assim, ressalta-se a atuação do Sistema Conselhos de Psicologia e do Centro de Referência Técnica em Psicologia e Políticas Públicas (Crepop), que realizaram seminários e publicaram documentos permeados de debates em torno da temática, no objetivo de dar 
conhecimento à categoria sobre questões relativas a terra e problemas enfrentados pelos povos indígenas, trabalhadores rurais sem terra, atingidos por barragens e povos tradicionais (CFP, 2006; CRPSP, 2010, 2016; Crepop, 2019a, 2019b). Porém, é válido lembrar que a questão agrária permeia uma série de outros problemas fundamentais da sociedade brasileira, não restrita apenas à luta pela distribuição de terras, mas relacionada à redistribuição da renda, poder e direitos, no sentido da busca por uma mudança na estrutura política e social do país (Silva, 1981). Trata-se de considerar o encontro com as realidades não apenas dos indígenas, quilombolas e trabalhadores rurais sem terra, mas das/os camponesas/es de forma geral, que inclui uma diversidade de atores sociais que vivem em contextos rurais (Godoi, Meneses \& Marin, 2009), entrando em contato com suas diferentes identidades, culturas e modos de vida.

Diante disso, este trabalho objetiva investigar como a produção do conhecimento brasileiro em Psicologia tem abordado o tema da questão agrária e como tem contribuído para produzir referências técnicas para a profissão. Considerando a novidade desse debate para a área, será apresentado, inicialmente, os principais elementos que embasam o debate sobre a "questão agrária" no Brasil, a fim de melhor orientar o olhar sob as primeiras incursões e entendimentos da Psicologia sobre o tema.

\section{A questão agrária no Brasil: breves considerações}

A questão agrária constitui um problema social oriundo da concentração da estrutura fundiária da terra, responsável por gerar concentração de riqueza e, por sua vez, desigualdades sociais e regionais (Girardi \& Fernandes, 2013). De acordo com Silva (1981), ela permeia uma série de problemas fundamentais da sociedade brasileira, relacionados à forma parasitária como se desenvolveu o capitalismo. Não deve ser pensada, pois, de maneira isolada, pois está agrupada com outras questões (alimentar, energética, indígena, ecológica, urbana e desigualdades regionais, entre outras). Além disso, deve ser concebida como indissociável da questão social. 
São diversas as contribuições a respeito da análise e do estudo da questão agrária no Brasil, com leituras que vão desde um enfoque na Economia Política e na História, passando por outras áreas do conhecimento, a exemplo da análise da evolução das classes sociais no campo, do desenvolvimento das forças produtivas, ou do desenvolvimento de lutas e movimentos sociais. No geral, tais enfoques têm ampla produção acadêmica, realizada por historiadores, cientistas políticos e por sociólogos, entre outros (Stedile, 2012).

A respeito do debate sobre a questão agrária no Brasil, conforme apontado por Nakatani, Faleiros e Vargas (2012), não houve mudanças substanciais na questão da propriedade fundiária no seu processo de crescimento e desenvolvimento econômico. No campo acadêmico e político, o debate sobre a questão agrária deu-se no fim da década de 1950. Isso demonstra que historicamente é muito recente o debate político que visa a soluções para o problema agrário no Brasil. Como se sabe, nos quatro séculos do período colonial-escravocrata, imobilizada pelo modelo agroexportador colonial, a sociedade contou com um lento desenvolvimento. Na realidade da escravidão, o alto grau de espoliação não permitiu que houvesse organização social e política no campo, sendo a fuga dos escravos considerada a única forma de luta (Stedile, 2012).

O Brasil foi ainda o último país a abolir a escravidão (1888) e um dos últimos do continente a ter adotado a República como governo (1889); uma República dominada pelas mesmas elites rurais que enriqueciam durante o colonialismo, tendo ocorrido de maneira imposta por golpe militar e pelos militares que serviam à monarquia. Durante o processo de crise da escravidão e do modelo agroexportador, levantaram-se apenas algumas vozes em torno da questão da terra no Brasil. Eram vozes da própria elite, associadas ainda a algumas manifestações culturais da época que condenavam o modelo agroexportador; mas, mesmo assim, não contavam com programas definidos de mudanças na estrutura fundiária (Stedile, 2012).

Ainda de acordo com o autor, com o arrastar dos anos, houve o agravamento da situação, considerando a miséria, o atraso e a ignorância advindos da persistência do problema do monopólio da terra, da propriedade privada da terra e da concentração da propriedade por uma minoria. Mas, por outro lado, com a organização da classe 
trabalhadora e operária brasileira em torno dos sindicatos e outras formas de organização política, levantou-se a bandeira da questão agrária como grande problema do país, culminando com as manifestações realizadas pela bancada eleita pelo Partido Comunista do Brasil (PCB), na Constituinte de 1946, com propostas para a realização da reforma agrária (Stedile, 2012).

O debate foi então fortalecido a partir de 1955 com as Ligas Camponesas, inicialmente presentes no Nordeste e depois em todo país, na reivindicação da reforma agrária. Porém, na década seguinte, em 1960, houve tentativas de negar a questão agrária devido ao desenvolvimento de uma política econômica de instabilidade política (Engelmann \& Gil, 2012). Ressalta-se que, entre 1960 e 1970, a concentração da posse das terras agravou-se devido à presença de grandes empresas multinacionais, quando o número de estabelecimentos agropecuários passou de 3,3 milhões para 4,9 milhões (Silva, 1981). Desse modo, a tentativa de negar a questão agrária foi uma situação alterada somente na década de 1980, com o fim do regime civil-militar, quando a reforma agrária voltou a ser discutida, porém, sob o contexto de industrialização e modernização da agricultura brasileira (Engelmann \& Gil, 2012).

Esse retorno à discussão da reforma agrária no contexto de modernização da agricultura se relaciona ao fato de esta ter sido marcada pela associação entre capital e propriedade fundiária, sem alteração da estrutura da propriedade rural. Isso teve efeitos perversos devido ao aumento da desigualdade. Assim, houve maior concentração da propriedade e aumento nas disparidades de renda. Ademais, houve o aumento do êxodo rural, já iniciado nos anos de 1960, assim como da taxa de exploração da força de trabalho nas atividades agrícolas e da taxa de autoexploração nas propriedades menores, além da piora na qualidade de vida da população trabalhadora do campo (Palmeira, 1989; Wanderley, 2011; Silva, 2013); por isso que o processo de modernização da agricultura foi denominado por Silva e Del Grossi (2000, p. 169) como "modernização conservadora".

É nesse contexto que se situam o agronegócio e o campesinato, que são os dois principais campos de debate e tensão da questão agrária brasileira (Girardi \& Fernandes, 2013). O agronegócio ganhou força com a crise econômica que o país viveu na década de 
1980, caracterizado pela exploração do trabalho assalariado, intensa mecanização, grandes propriedades de terra, especulação imobiliária, danos ambientais em grande escala, monocultura, produção majoritária para exportação e concentração do poder político e econômico (Girardi \& Fernandes, 2013). Na visão de Fernandes (s/d), isso tem se dado com o enfraquecimento do campesinato, concentração, dominação, exploração e desigualdade. Quanto ao campesinato, "a prática faz aparecer uma infinidade de possibilidades e arranjos, vividos até mesmo por um mesmo grupo" (Fernandes, s/d, p. 11); mas, em termos gerais, pode ser compreendido como "categoria analítica e histórica, sendo constituído por poliprodutores, integrados ao jogo de forças sociais do mundo contemporâneo" (p. 9), tendo como luta principal a "construção de seu patrimônio, condição sine qua non de sua existência (p. 15). ${ }^{3}$

Aqui cabe um alerta para as/os psicólogas/os que têm se inserido nesse debate. $O$ histórico desencontro da profissão com a questão social e rural, e o próprio desencontro com a questão agrária, que é indissociável da questão social, precisam ser problematizados.

A aproximação da Psicologia com contextos rurais tem aberto, assim, novas linhas de discussões e questionamentos, acompanhados de inúmeros desafios para a profissão. A questão agrária é um deles, fato que exige um entendimento mais amplo e crítico da Psicologia sobre a temática, configurando-se como um campo que convoca psicólogas/os a novas leituras, posturas e lutas, bem como um posicionamento ético-político que não se ancore em perspectivas "dualistas e universalistas", acompanhadas de uma "racionalidade instrumental que desconsidera a multiplicidade de formas de vida, a existência de diferentes mundos, a heterogeneidade espacial, social e simbólica que caracteriza os territórios" que constituem os contextos e os povos rurais no Brasil (Dimenstein et al., 2018, p. 81).

\footnotetext{
3 Citações do Conselho editorial na apresentação à coleção: “Điversidade do campesinato: expressões e categorias. Estratégias de reprodução Social”, organizada por Godoi, Menezes e Marin (2009).
} 


\section{Método}

Trata-se de um estudo bibliográfico realizado na base de dados Scientific Electronic Library Online (SciELO), em janeiro de 2017. Inicialmente, o critério para a escolha do material foi a produção científica em periódicos que incluísse os descritores "Psicologia" e "terra", "Psicologia" e "agrária/o" em periódicos nacionais. O intuito era recorrer a termos que abarcassem um panorama geral das publicações sobre o tema na literatura nacional. Nesse primeiro levantamento, foi localizado o total de 44 artigos, sendo realizada a leitura na íntegra dos resumos destes para identificarmos se traziam elementos do universo da questão agrária/questão da terra.

Dos 44 artigos elegíveis e acessados, três eram de autores estrangeiros e estavam apresentados em outras línguas, quatro estavam duplicados, 15 não tratavam sobre o tema e quatro, apesar de contarem com temas sobre o universo da questão agrária, tratavam sobre o assunto de maneira marginal/pontual em seus aspectos teóricos e/ou analíticos, por isso foram descartados desta investigação. Restaram 18 artigos, sendo oito trabalhos teóricos e 10 empíricos, que formaram o corpus da pesquisa.

Procedeu-se à leitura na íntegra dos 18 artigos, com o objetivo de identificarmos os pontos centrais de cada trabalho, considerando como aspectos principais a maneira como os temas "questão agrária" e "questão da terra" eram tratados em cada um, considerando as definições, problematizações, delineamento do estudo, participantes e a relação com a Psicologia. O material foi analisado a partir a) dos entendimentos da Psicologia acerca da questão agrária; e b) com base nas abordagens teóricas, analíticas e práticas da Psicologia a respeito da questão agrária.

\section{A Psicologia e o universo da questão agrária}

Os artigos identificados que versaram sobre a relação entre a Psicologia e o universo da questão agrária e das questões da terra $(n=18)$, no geral, trataram sobre assentamentos, acampamentos, cooperativas e Movimento dos Trabalhadores Rurais Sem 
Terra (MST). A figura de trabalhadoras/es rurais, pequenas/os produtoras/es e assentadas/os que lutam pela terra e por melhores condições de vida e de trabalho constituem os principais sujeitos dos estudos.

Incluída em grande parte das pesquisas, está a reforma agrária, sendo abordada principalmente no seu sentido clássico de luta pela terra. As pesquisas de Albuquerque et al. (2005), Albuquerque, Coelho e Vasconcelos (2004), Albuquerque, Vasconcelos e Coelho (2004), Alvaides e Scopinho (2013), Figueiredo e Pinto (2014), Scopinho (2013), Silva (2013) e Velôso e Whitaker (2013) abordam sobre a reforma agrária.

Quanto a isso, Albuquerque et al. (2005) destacaram os projetos de assentamento como uma das ações da reforma agrária que visa a contribuir para o desenvolvimento rural do Brasil - o estudo versou sobre a integração entre assentadas/os agrários/as e comunidades vizinhas, focando nos impactos socais, políticos e econômicos que os assentamentos podem gerar nas comunidades locais. Para Albuquerque, Vasconcelos e Coelho (2004), a reforma agrária é considerada um processo complexo e difícil de entender e de superar, destacando, Ainda, a escassez de estudos direcionados aos fatores psicológicos ou psicossociais dos diversos grupos envolvidos. Alvaides e Scopinho (2013), ao analisarem a memória no processo de enraizamento e de reconstrução da identidade social de trabalhadoras/es em assentamentos de reforma agrária, verificaram que continuam se identificando como trabalhadores sem-terra, apesar de já terem sido assentadas/os; ademais, chegaram à conclusão de que a luta pela terra vai além da busca por lote de reforma agrária, sendo uma luta política que visa à garantia de direitos sociais.

Em relação a isso, Carter (2010, p. 71) nos lembra de que o debate em vigor no Brasil sobre a reforma agrária vai além de assuntos relacionados à questão fundiária e ao desenvolvimento rural: "Os assuntos em pauta levantam problemas mais profundos da sociedade brasileira. Na alvorada do século XXI, a reforma agrária continua sendo parte de uma conversação complexa e contenciosa sobre o futuro do Brasil - suas promessas e necessidades, seus temores e sonhos".

Partindo dessas reflexões, é possível identificar que, apesar do processo de reforma agrária estar referido pela Psicologia em seus estudos, ainda concentra as discussões quase 
que exclusivamente sob a realidade de assentadas/os, acampadas/os, trabalhadoras/es rurais e pequenas/os produtoras/es na luta pela terra. Desse modo, existe uma escassez de investigações a respeito da questão agrária que tenha por base as existências e perspectivas de outros sujeitos que vivenciam os conflitos de luta pela terra, como os povos tradicionais, abordado, até então, apenas no trabalho de Lemos e Galindo (2013).

A variedade de sujeitos precisa então ser considerada na compreensão da problemática da questão agrária brasileira. Little (2002), em sua discussão sobre "povos rurais", pontua que são várias as formas de grupos humanos; nesse sentido, vão desde sociedades indígenas a outras distintas formas fundiárias, o que evidencia a imensa diversidade sociocultural e fundiária brasileira. Trata-se de "populações", "comunidades", "povos", "sociedades", "culturas", cada qual adjetivada com expressões como "tradicionais", "autóctones", "rurais", “locais", "residentes" (Little, 2002, p. 2).

Em meio a essa diversidade fundiária, suas definições e classificações, que podem ser encontradas na literatura especializada nos trabalhos de Diegues (2000), Diegues et al. (2000) e Brandão (200-), é preciso ressaltar a emergência de um novo nominalismo que surgiu na contemporaneidade na identificação de novos atores sociais na cena política como povos ou comunidades tradicionais: seringueiros, quilombolas, ribeirinhos, caiçaras, pescadores, entre outros (Almeida, 2007). Isso demonstra que a diversidade de formas fundiárias e das distintas maneiras de defini-las requisita esforço para a compreensão de suas características, de maneira que a inserção no debate sobre a questão agrária requer a compreensão dessas especificidades.

Tal diversidade, ao revelar a grande extensão do território do campesinato - que disputa com o território do agronegócio, antes referidos -, requisita dos trabalhos de pesquisa que se voltem sobre suas singularidades, as quais são compostas por contextos que ainda são marcados pela persistência do trabalho escravo contemporâneo, aprofundamento da fome e da pobreza, não realização do projeto de reforma agrária e ampliação dos conflitos por terra. Sendo assim, as/os pequenas/os agricultoras/es, camponesas/es, povos indígenas, quilombolas e outros grupos sociais continuam mais e 
mais marginalizados e destituídos não apenas de suas terras, mas de modos tradicionais de vida, devido ao favorecimento do agronegócio (Fernandes, Welch \& Gonçalves, 2013).

Alguns aspectos relativos ao campesinato e agronegócio foram identificados nos trabalhos de Albuquerque (2002), Leite e Dimenstein (2006, 2010), Lemos e Galindo (2013) e Silva (2010, 2013). Para Albuquerque (2002) e Silva (2010), o Brasil optou por um modelo de desenvolvimento agrário que financia e incentiva a agricultura de larga escala, em detrimento da agricultura familiar, tendo como consequência a grande disparidade de renda e de qualidade de vida das populações. Interessado na conflitualidade entre campesinato e capital, Silva (2013) afirmou, ainda em outro trabalho, a centralidade dessa disputa territorial e a importância da produção de subjetividades atreladas a essa territorialidade. Por sua vez, Lemos e Galindo (2013) deram destaque para a realidade de povos indígenas e dos chamados povos tradicionais, devido ao cenário de violência e assassinatos, em meio à disputa e avanço do agronegócio, além dos conflitos em torno do desmatamento, extração e venda de recursos como minérios e madeira, construção de estradas, entre outros.

A importância de compreender essas disputas territoriais se deve ao fato de elas conformarem a conflitualidade, um conceito que tem sido utilizado nos debates da questão agrária atual, responsável por gerar o desenvolvimento por meio do embate de forças entre os diferentes territórios, numa associação entre conflito e desenvolvimento (Fernandes, Welch \& Gonçalves, 2013; Felício \& Fernandes, 2013). Situações como ocupações de terra e a instalação de acampamentos e assentamentos rurais são exemplos de conflitualidade na disputa por terras, podendo, inclusive, desdobrarem-se em situações de violência, como expulsões e despejos de terra, assassinatos e ameaças de morte (Girardi \& Fernandes, 2013).

Por meio da análise da conflitualidade, tem-se demonstrado que o desenvolvimento do capitalismo no campo brasileiro tem ocorrido à base do contínuo processo de expropriação e exploração de povos tradicionais. Apesar das derrotas advindas com a chamada "modernização do campo", os povos tradicionais têm conseguido duramente manter a sua cultura, focos de resistência, e a relação com a natureza. Ao terem a terra como modo de vida, esses povos têm que disputá-la com as empresas que a veem como 
meio para exploração e lucro (Fernandes, Welch \& Gonçalves, 2013). Tais aspectos podem compor um importante campo de investimento para as pesquisas em Psicologia, no sentido de contribuir na compreensão da conflitualidade em contextos variados.

O MST - principal movimento camponês na luta pela terra, que visa ao assentamento de famílias sem terra, com ênfase para a criação de políticas para o desenvolvimento e autonomia dos territórios (Fernandes, Welch \& Gonçalves, 2013) - é citado ou discutido de maneira específica na maioria dos trabalhos. Tratam sobre o tema as pesquisas de Domingues (2007), Leite e Dimenstein (2006, 2010), Rosa e Silva (2015) e Silva (2010, 2013). Com diferentes abordagens, os trabalhos ajudam a pensar sobre o contexto de formação desse movimento e o processo de formação política (subjetivação política) envolvido.

Leite e Dimenstein (2010), por exemplo, deram uma importante contribuição ao terem trazido uma visão ampliada acerca da luta do MST, entendendo-a para além do acesso a terra, voltada para um projeto de transformação social aliado à busca por direitos sociais. Atualmente o combate ao agronegócio destaca-se como importante bandeira de luta, situação que coloca o MST num "novo lugar social ao levantar questões que extrapolam o universo clássico de sua gênese: a luta pela terra e a reforma agrária" (Leite \& Dimenstein, 2010, p. 271).

Esse entendimento reforça o que já vem sendo discutido na literatura: que apesar de a modernização forçada do campo ter gerado problemas sociais, do domínio do agronegócio, que rompeu com visões e vivências tradicionais de tempo e espaço rural e consequentes modos de vida (Brandão, 2007), além da expropriação de trabalhadoras/es das grandes propriedades, por outro lado, houve grande e crescente número de pequenas/os agricultoras/es que, de maneiras distintas, mantiveram a capacidade de organizar uma atividade produtiva (Wanderley, 2011). A resistência ativa de grupos e comunidades expropriados não pode ser desconsiderada.

Nessas lutas camponesas, a reforma agrária é tida como política de desenvolvimento necessária para a distribuição de terra a partir do questionamento da concentração da estrutura fundiária (Engelmann \& Gil, 2012). De maneira geral, a reforma agrária é 
considerada como necessidade historicamente defendida para a resolução dos problemas agrários no Brasil; e para que avance em sua radicalidade deve, simultaneamente, reformar a estrutura fundiária, possibilitar o acesso de camponesas/es à terra e fornecer-lhes condições básicas de vida e produção (Girardi \& Fernandes, 2013). No entanto, conforme alerta Engelmann e Gil (2012, p. 8) "a reforma agrária no Brasil representa um problema histórico que as classes dominantes até hoje não tiveram interesse em resolver".

Isso demonstra que na realização da reforma agrária vários fatores se fazem presentes, o que a torna não apenas um problema agrário, do campo e relativo a determinados grupos, mas a toda sociedade. O estudo de Albuquerque, Coelho e Vasconcelos (2004) pontua que no conjunto das políticas voltadas para o setor agrário reproduz-se a associação com a ideia de interior, deixando de investir em outras formas de desenvolvimento rural que não estejam necessariamente vinculadas ao universo "agro". Nessa mesma direção, Albuquerque (2002) sugeriu a importância de apreender o mundo rural para além da produção agrária, por exemplo, as pequenas indústrias, o comércio, os serviços e as aposentadorias, constituindo-se assim como vetores fundamentais de recursos para os pequenos municípios brasileiros.

Apesar da riqueza de possibilidades investigativas, verificou-se, a partir do material reunido nesse primeiro bloco de resultados, que a produção da Psicologia acerca da questão agrária ainda é pequena. Além disso, os estudos estão concentrados primordialmente nas regiões Sudeste e Nordeste, o que demonstra a enorme lacuna a respeito das especificidades regionais. Desse modo, cabe à Psicologia fortalecer o seu conhecimento a respeito do processo histórico de conformação da questão fundiária; dos atores sociais, agentes institucionais e forças políticas envolvidas; das dinâmicas, processos e lutas sociais; além dos fatores culturais, ambientais, psicossociais e indentitários envolvidos. Trata-se de um grande desafio para a área, que por muito tempo manteve-se à margem das discussões sobre a questão social e rural, e só recentemente vem se aproximando desses campos, especialmente por meio de sua atuação nas políticas sociais. 


\section{Contribuições da Psicologia para o debate sobre a questão agrária}

Sobre as contribuições da produção de conhecimento em Psicologia para o debate da questão agrária, percebe-se que o campo de preocupações dos estudos está quase que exclusivamente voltado à própria área, sendo escassas as leituras e os investimentos conceituais em outras áreas do conhecimento. Entre as questões abordadas nas pesquisas, sobressai o tema da subjetividade, como é possível encontrar nos trabalhos de Alvaides e Scopinho (2013), Figueiredo e Pinto (2014), Leite e Dimenstein (2006, 2010), Lopes (2007) e Vasquez (2009).

Figueiredo e Pinto (2014) se propuseram a discutir a participação de indivíduos assentados ligados ao MST no movimento de luta pela reforma agrária. A pesquisa deles sugere que o individuo, ao participar da luta pela terra, adquire uma experiência de si próprio como indivíduo singular e ao mesmo tempo cria um significado coletivo e transformador de sua própria subjetividade. De acordo com os autores, a partir dessa experiência coletiva as pessoas reorganizam sua subjetividade. Seguindo a mesma direção, Leite e Dimenstein (2006) discutiram acerca dos processos de subjetivação dos trabalhadoras/es sem-terra acampadas/os vinculadas/os ao MST, entendendo que a práxis coletiva desses processos reverbera nas subjetividades desses sujeitos. Em outro trabalho, Leite e Dimenstein (2010) se voltaram para os movimentos sociais a partir dos processos de subjetivação e evidenciaram a perspectiva de subjetividade como processo e produção, superando a dicotomia interioridade-exterioridade.

Para Lopes (2007), a compreensão do espaço como substrato para a constituição da subjetividade constitui-se como uma das referências centrais da questão social da terra para a Psicologia. De acordo com o autor, é necessário que a "Psicologia esclareça alguns processos da reconstrução das relações intersubjetivas orientadas pelas racionalidades dos sujeitos envolvidos nas lutas sociais pela terra" (Lopes, 2007, p. 591).

O campo de conhecimento priorizado pelas pesquisas foi a Psicologia Social. Aqui cabe destacar os trabalhos de Albuquerque (2002), Albuquerque et al. (2005), Albuquerque, Coelho e Vasconcelos (2004) e Albuquerque, Vasconcelos e Coelho (2004), que 
demonstraram a aplicabilidade da Psicologia Social na modificação das relações entre grupos e entre membros de um mesmo grupo, além de contribuir para a compreensão de aspectos psicossociais. A análise comportamental foi outro aspecto encontrando de competência da Psicologia Social para atuar nesse campo (Albuquerque et al., 2005). Alvaides e Scopinho (2013) destacaram outra contribuição, aquela relativa ao entendimento da memória como constitutiva de subjetividades e identidades, no sentido de entender como são estruturadas as relações sociais vivenciadas pelo sujeito e como participa delas.

Outros exemplos de metodologias, envolvendo grupos, também foram mencionados, com a finalidade de estabelecer novas relações entre os/as participantes, além do fortalecimento do processo de integração, utilizando conceitos como coesão grupal e aspectos de liderança. No seu trabalho com grupos de mulheres assentadas, Vasquez (2009) considerou os assentamentos como espaços de reprodução da vida, sendo um local que permite a construção e reconstrução da subjetividade. Nesse sentido, a pesquisa em grupo buscou trabalhar a autoimagem, a autoestima, a autoconfiança e a autonomia dessas mulheres, contribuindo para a reorganização de suas subjetividades.

Além da abordagem sobre grupo, outra categoria analítica clássica da Psicologia Social reconhecida no material selecionado foi a respeito da identidade social. Aqui estão incluídas as pesquisas de Albuquerque (2002), Albuquerque et al. (2005), Albuquerque, Vasconcelos e Coelho (2004), Alvaides e Scopinho (2013) e Figueiredo e Pinto (2014).

As análises de Albuquerque et al. (2005) indicam que um projeto de assentamento não se caracteriza somente por ajudar a suprir as necessidades econômicas e de infraestrutura, sendo um local de trabalho e moradia onde se constroem a identidade social. Para Albuquerque, Vasconcelos e Coelho (2004), a teoria da identidade social colabora para a análise psicossocial dos fenômenos ocorridos nos assentamentos e em seu entorno, entendendo que estes propiciam um ambiente que ajuda na construção de uma identidade social. Alvaides e Scopinho (2013), por sua vez, procuraram compreender como a memória participa do processo de enraizamento e reconstrução da identidade social de trabalhadoras/es. A pesquisa deles sugere que, "ao ser excluído da rede social de pertencimento, o sujeito afasta-se dos seus valores, ideologias, costumes e crenças e 
encontra dificuldades de ordem objetiva e subjetiva para realizar-se e reproduzir-se como ser social" (Alvaides \& Scopinho, 2013, p. 289). Para Figueiredo e Pinto (2014), a luta pela terra é uma experiência singular, na qual os sujeitos reorganizariam sua identidade social.

Albuquerque, Coelho e Vasconcelos (2004), Albuquerque, Vasconcelos e Coelho (2004) e Silva (2010) demonstram ainda a escassez de investigações que versam sobre os aspectos psicossociais nesses contextos no âmbito da Psicologia Social. Suas pesquisas sugerem a importância de atentar-se para a existência de grandes diferenças psicossociais, embora as pessoas estejam convivendo no mesmo espaço territorial e sofram com as mesmas situações.

Apesar da carência de estudos envolvendo aspectos psicossociais nesse campo, foi possível verificar um tema importante que tem sido abordado pelas/os pesquisadoras/es na área. Trata-se da relação com a esfera política, como é o caso dos trabalhos de Figueiredo e Pinto (2014), Leite e Dimenstein (2010), Rosa e Silva (2015), Silva (2010) e Vasquez (2009).

Figueiredo e Pinto (2014), por exemplo, sinalizaram que a participação na luta pela terra estimula o desenvolvimento da posição crítica das/os integrantes, contribuindo para sua autonomia e emancipação. Rosa e Silva (2015), por sua vez, demonstraram que a dimensão política não se relaciona apenas ao movimento social, mas à própria vida das pessoas. A pesquisa de Silva (2010) interessou-se pelos aspectos psicopolíticos da luta pela terra empreendida pelo MST, sugerindo que existe uma relação entre elementos psicológicos e políticos nas questões agrárias. Vasquez (2009), a partir de sua intervenção em grupo, referida anteriormente, acentuou a importância de conceber as intervenções não apenas direcionadas para questões subjetivas, mas também para a realidade cotidiana dos assentamentos, com suas relações instituídas.

Outro tema abordado se relaciona às questões de gênero, que apareceram nas pesquisas de Albuquerque (2002) e Vasquez (2009). São trabalhos que abordaram as diferenças de gênero, sugerindo a importância de que tanto as políticas públicas quanto as ações profissionais atentem para essas especificidades. Rosa e Silva (2015) demonstraram no estudo com uma militante do MST que existe uma transformação no sentido da militância, mas também no sentido da transformação como mulher. 
Por fim, cabe mencionar uma questão importante, levantada por Lemos e Galindo (2013), no estudo sobre o massacre e a resistência dos povos indígenas Kaiowá e Guarani. De acordo com as autoras, houve na realidade investigada "demandas por práticas psicológicas tolerantes baseadas na patologização e na explicação de base individualizante pautadas por subjetivações definidas por maneiras aceitáveis de ser índio" (Lemos \& Galindo, 2013, p. 986). É o que tanto o Estado quanto as agências multilaterais demandam da atuação de psicólogas/os, ou seja, "como dispositivo de tolerância expresso na patologização de base etnocêntrica" (p. 986).

Por isso a importância de considerar de forma crítica a complexidade e a diversidade de aspectos relacionados à questão agrária no país, e ao mesmo tempo ampliar as possibilidades de compreensão e intervenção psicológica nesse campo. Assim, é necessário que a Psicologia se desligue de sua herança epistêmica moderna/colonial (Bermúdez, 2011) que a fez desconsiderar tudo aquilo que não se encaixava na lógica do mundo racional moderno-colonial europeu (Góis et al., 2016).

\section{Considerações finais}

Refletir sobre as incursões da Psicologia no debate sobre a questão agrária requer considerar o que já se tem produzido nesse campo e problematizar as lacunas, no sentido de acompanhar o debate realizado pela literatura especializada em outras áreas. Assim, propor outros elementos teóricos, analíticos e práticos a fim de contribuir para o crescimento e qualificação no debate sobre a questão agrária no Brasil.

Os resultados encontrados sugerem que são muitos os desafios a serem superados pela Psicologia no seu encontro com a questão agrária. Como foi possível identificar, a escassez dos estudos nessa área se explica pelo próprio distanciamento da Psicologia em relação à categoria rural e às diversidades e particularidades latino-americanas e brasileiras. De fato, a Psicologia acabou focalizando sua atenção na realidade das populações urbanas e construindo conhecimentos a partir de um único modelo de ser humano, como discutido por Alves e Delmondez (2015). Daí autores como Lucena Filho e Silva (2018) defenderem a 
necessidade de questionar a permanência e a reprodução dos colonialismos nas teorias e práticas profissionais da Psicologia.

De maneira específica, é preciso aprofundar-se em pesquisas sobre a ampliação de sentidos referidos a rural, para além de uma dimensão concreta, para que abarque aspectos simbólicos, relações de poder, identidades, saberes, modos de vida e disputas, no sentido de compreender de maneira qualificada as dinâmicas e processos presentes na questão agrária brasileira. De tal modo, na discussão sobre a questão agrária, a Psicologia pode qualificar o debate acerca da ampliação da concepção de rural.

Ademais, essa ampliação do olhar acerca do rural passa pela necessidade de avançar em pesquisas sobre povos rurais. Como referido alhures, a maioria das pesquisas identificadas neste estudo versa basicamente sobre problemáticas da questão agrária em torno de assentadas/os, pequenas/os produtoras/es e trabalhadoras/es acampadas/os, apesar de existir enorme diversidade fundiária, definições e classificações quando se trata de povos rurais. Da mesma forma que rural não se resume a agrícola, esses povos não devem ser entendidos apenas como instrumentos da produção agrícola (Martins, 2001).

A inserção da Psicologia no debate sobre a questão agrária exige da profissão um ir além da problemática de trabalhadoras/es sem terra que lutam por direitos e melhoria de condições de vida, pois versa sobre as realidades de crianças, jovens, adultas/os e idosas/os; índias/os, quilombolas, agricultoras/es familiares, e demais indivíduos incluídos no novo nominalismo (Almeida, 2007). Isso interpela psicólogas/os sobre a diversidade de formas fundiárias e os valores e significados nelas produzidos e reproduzidos sobre infância, juventude, fase adulta, velhice, e relações de gênero e geracionais em sua atuação e pesquisa em contextos rurais e em questões relativas a terra.

Com a isso, a Psicologia poderia contribuir no sentido de ampliar o olhar para as diferenças, diversidades e singularidades que marcam a existência e o cotidiano das diferentes pessoas, grupos e povos que vivem em contextos rurais brasileiros e latinoamericanos, avançando também no conhecimento das culturas subalternas e profundas na América Latina. Como afirmado anteriormente por Góis et al. (2016), esses são aspectos e problematizações que ainda são pouco considerados no contexto acadêmico da América. 
Por isso a importância de atentar para os diferentes modos de vida, subjetividades, disputas territoriais, contextos de formação de cultura e identidade na realidade de povos rurais, pois eles expressam a singularidade de suas necessidades e potencialidades, que, como pode ser verificada, não se restringem apenas à problemática do acesso a terra e da convivência em grupo, ampliando os próprios sentidos acerca da questão agrária, não resumida apenas ao agrário.

\section{Referências}

Albuquerque, F. J. B. (2001). Aproximación metodológica desde la Psicología Social a la investigación en zonas rurales. Estudios Agrosociales y Pesqueros, (191), 225-233.

Albuquerque, F. J. B. (2002). Psicologia Social e formas de vida rural no Brasil. Psicologia: Teoria e Pesquisa, 18(1), 37-42.

Albuquerque, F. J. B. et al. F (2005). Integração entre assentados agrários e comunidades vizinhas. Psicologia em Estudo, 10(3), 499-506. Recuperado de http://www.scielo.br/pdf/pe/v10n3/v10n3al 7.pdf.

Albuquerque, F. J. B., Coelho, J. A. P. M., \& Vasconcelos, T. C. (2004). As políticas públicas e os projetos de assentamento. Estudos de Psicologia, 9(1), 81-88. Recuperado de http://www.scielo.br/pdf/epsic/v9n1/22384.pdf.

Albuquerque, F. J. B., Vasconcelos, T. C., \& Coelho, J. A. P. M. (2004). Análise psicossocial do assentamento e seu entorno. Psicologia: Reflexão e Crítica, 17(2), 233-242. Recuperado de https://www.scielo.br/scielo.php?pid=S010279722004000200011 \&script $=$ sci_arttext $\&$ tlng $=$ pt.

Almeida, M. W. (2007). Narrativas agrárias e morte do campesinato. RURIS, 1(2), 157-188. Recuperado de http://www.ifch.unicamp.br/ojs/index.php/ruris/article/view/656/523. 
Alvaides, N. K., \& Scopinho, R. A. (2013). De sem-terra a sem-terra: memórias e identidades. Psicologia \& Sociedade, 25(2), 288-297. Recuperado de http://www.scielo.br/pdf/psoc/v25n2/06.pdf.

Alves, C. B., \& Delmondez, P. (2015). Contribuições do pensamento decolonial à Psicologia Política. Psicologia política, 15(34), 647-661.

Brandão, C. R. (2007). Tempos e espaços nos mundos rurais do Brasil. RURIS, 1(1), 37-64. Recuperado de http://www.ifch.unicamp.br/ceres/037-064carlos_rodrigues.pdf

Brandão, C. R. (200-). A comunidade tradicional. Recuperado de http://nupaub.fflch.usp.br/sites/nupaub.fflch.usp.br/files/a\%20comunidade\%20trad 160.pdf.

Campos, R. H. F. (Org.). (1998). Psicologia Social Comunitária: da solidariedade à autonomia. Petrópolis: Vozes.

Carneiro, M. J. (2008). "Rural" como categoria de pensamento. Rurais, 2(1), 9-38. Recuperado de http://www.ifch.unicamp.br/ojs/index.php/ruris/article/view/661/528.

Carneiro, M. J. (2012). Finalizando: no caminho de um rural incerto. In M. J. Carneiro (Org.). Ruralidades contemporâneas: modos de viver e pensar o rural na sociedade brasileira (pp. 247-254). Rio de Janeiro: Mauad X: Faperj.

Carter, M. (2010). Desigualdade social, democracia e reforma agrária no Brasil. In M. Carter. (Org.). Combatendo a desigualdade social: o MST e a reforma agrária no Brasil (pp. 27-78). São Paulo: Editora Unesp.

Centro de Referência Técnica em Psicologia e Políticas Públicas. (2019a). Referências técnicas para atuação de psicólogas(os) em questões relativas à terra. Conselho Federal de Psicologia: Brasília, DF. 
Centro de Referência Técnica em Psicologia e Políticas Públicas. (2019b). Referências técnicas para atuação de psicólogas(os) para a atuação de psicólogas(os) com povos tradicionais. Conselho Federal de Psicologia: Brasília, DF.

Conselho Federal de Psicologia. (2006). Seminário Nacional: a questão da terra - desafios para a Psicologia. CFP: Brasília, DF. Recuperado de https:// site.cfp.org.br/publicacao/seminrio-nacional-a-questo-da-terra-desafiospara-a-psicologia/.

Conselho Regional de Psicologia de São Paulo. (2010). Psicologia e povos indígenas. São Paulo: CRPSP.

Conselho Regional de Psicologia de São Paulo. (2016). Povos indígenas e Psicologia: a procura do bem viver. São Paulo: CRPSP.

Dantas et al. (2018). A pesquisa em contextos rurais: desafios éticos e metodológicos para a Psicologia. Psicologia \& Sociedade, 30, 1-10. Recuperado de http://www.scielo.br/pdf/psoc/v30/1807-0310-psoc-30-e165477.pdf.

Diegues, A. C. (2000). O mito moderno da natureza intocada. São Paulo: Hucitec; Núcleo de Apoio à Pesquisa sobre Populações Humanas e Áreas Úmidas Brasileiras, USP.

Diegues, A. C., et al. (2000). Os saberes tradicionais e a biodiversidade no Brasil. São Paulo.

Dimenstein, M. (2000). A cultura profissional do psicólogo e o ideário individualista: implicações para a prática no campo da assistência pública à saúde. Estudos de Psicologia, 5(1), 95-121.

Dimenstein, M. et al. (2018). A saúde mental e atenção psicossocial: regionalização e gestão do cuidado integral no SUS. Salud \& Sociedad, 9(1), 70-85. Recuperado de https: / / dialnet.unirioja.es / servlet/articulo?codigo $=6755334$. 
Domingues, E. (2007). Vinte anos do MST: a Psicologia nesta história. Psicologia em Estudo, 12(3), 573-582. Recuperado de http://www.scielo.br/pdf/pe/v12n3/v12n3a14.pdf.

Engelmann, S. I., \& Gil, A. D. (2012). A questão agrária no Brasil: a política agrária do governo Lula e a relação com o MST. Revista Eletrônica do CEMOP, (2). Recuperado de http://www.memoriaoperaria.org.br/revistaeletronica/solange_e_aldo_duran.pdf.

Felício, M. J., \& Fernandes, B. M. (2013). A conflitualidade dos projetos de desenvolvimento rural a partir dos conceitos camponês/agricultor familiar. In B. M. Fernandes (Org.). Construindo um estilo de pensamento na questão agrária: o debate paradigmático e o conhecimento geográfico (pp. 52-66). Presidente Prudente.

Fernandes, B. M. (s/d). Agronegócio e Reforma Agrária. Recuperado de http://www2.fct.unesp.br/nera/publicacoes/AgronegocioeReformaAgrariA_Bernardo. pdf.

Fernandes, B. M., Welch, C. A., \& Gonçalves, E. C. (2013). Políticas fundiárias no Brasil: uma análise geo-histórica da governança da terra no brasil. In B. M. Fernandes (Org.). Construindo um estilo de pensamento na questão agrária: o debate paradigmático e o conhecimento geográfico (pp. 67-151). Presidente Prudente.

Ferraz, I. T., \& Domingues, E. (2016). A Psicologia Brasileira e os povos indígenas: atualização do estado da arte. Psicologia: Ciência e Profissão, 36(3), 682-695. Recuperado de http://www.scielo.br/pdf/pcp/v36n3/1982-3703-pcp-36-30682.pdf.

Figueiredo, G. C., \& Pinto, J. M. R. (2014). Acampamento e assentamento: participação, experiência e vivência em dois momentos da luta pela terra. Psicologia \& Sociedade, 26(3), 562-571. Recuperado de http://www.scielo.br/pdf/psoc/v26n3/a05v26n3.pdf. 
Girardi, E. P., \& Fernandes, B. M. (2013). Campesinato, agronegócio e latifúndio: territórios da questão agrária e a fronteira agropecuária brasileira. In B. M. Fernandes (Org.). Construindo um estilo de pensamento na questão agrária: o debate paradigmático e o conhecimento geográfico (pp. 33-51). Presidente Prudente.

Godoi, E. P., Menezes, M. A., \& Marin, A. (2009). Apresentação da coleção história social do campesinato brasileiro. In E. P. Godoi (Org.). Diversidade do campesinato: expressões e categorias: construções identitárias e sociabilidades (pp. 23-36). Brasília: Ed. da Unesp.

Góis et al. (2016). O conceito de América profunda e suas implicações na Psicologia Comunitária de base latinoamericana. In V. M. Ximenes, J. C. Sarriera, Z. Á. C. Bonfim \& J. Alfaro I. (Orgs.). Psicologia Comunitária no mundo atual: desafios, limites e fazeres (pp. 235-250). Fortaleza, CE: Expressão Gráfica e Editora.

leno Neto, G. et al. (1985). Uma experiência de trabalho no meio rural. Psicologia: Ciência e Profissão, 5(2), 27-31. Recuperado de http://www.scielo.br/pdf/pcp/v5n2/07.pdf.

Kay, C. (2002). Estructura agraria y violencia en la sociedad rural de América Latina. In Associação Latino-Americana de Sociologia Rural (Org.). VI Congresso da Associação Latino-Americana de Sociologia Rural (pp. 2139-2147). Universidade Federal do Rio Grande do Sul, Porto Alegre.

Leite, J. F., \& Dimenstein, M. (2006). Subjetividade em movimento: o MST no Rio Grande do Norte. Psicologia \& Sociedade, 18(1), 21-30. Recuperado de http:/ /www.scielo.br/pdf/psoc/v18n1/a04v18n1.pdf.

Leite, J. F., \& Dimenstein, M. (2010). Movimentos sociais e produção de subjetividade: o MST em perspectiva. Psicologia \& Sociedade, 22(2), 269-278. Recuperado de http://www.scielo.br/pdf/psoc/v22n2/07.pdf. 
Leite, J. F., et al. (2013). A formação em Psicologia para a atuação em contextos rurais. In J. F. Leite \& M. Dimenstein (Orgs.). Psicologia e contextos rurais (pp. 27-55). Natal: EDUFRN.

Lemos, F. C. S., \& Galindo, D. C. G. (2013). Massacre e resistência Kaiowá e Guarani: interrogações às Psicologias nos traçados do intolerável. Psicologia: Ciência $e$ $\begin{array}{llll}\text { Profissão, } & 33(4), & \text { 976-987. } & \text { Recuperado }\end{array}$ http://www.scielo.br/pdf/pcp/v33n4/v33n4a15.pdf.

Little, P. E. (2002). Territórios sociais e povos tradicionais no Brasil: por uma antropologia da territorialidade. Brasília.

Lopes, J. R. (2007). A questão social da terra como desafio para a Psicologia. Psicologia em Estudo, 12(3), 583-592. $\quad$ Recuperado de http://www.scielo.br/pdf/pe/v12n3/v12n3a15.

Lucena Filho, E. L., \& Silva, I. L. (2018). O processo de colonização e os possíveis impactos na Psicologia da atualidade. Psicologia \& Saberes, 7(9), 107-117. Recuperado de https://revistas.cesmac.edu.br/index.php/psicologia/article/view/857.

Martins, J. S. (2001). O futuro da Sociologia Rural e sua contribuição para a qualidade de vida rural. Estudos avançados, 15(43).

Nakatani, P., Faleiros, R. N., \& Vargas, N. C. (2012). Histórico e os limites da reforma agrária na contemporaneidade brasileira. Serv. Soc. Soc., (110), 213-240. Recuperado de http://www.scielo.br/pdf/sssoc/n110/a02n110.pdf.

Palmeira, M. (1989). Modernização, Estado e questão agrária. Estudos avançados, (17), 87108. Recuperado de http://www.scielo.br/pdf/ea/v3n7/v3n7a06.pdf. 
Rosa, L. A., \& Silva, A. P. S. (2015). Sujeito político dramático: mudanças vivenciadas por uma militante do MST. Psicologia \& Sociedade, 27(1), 47-57. Recuperado de http://www.scielo.br/pdf/psoc/v27n1/1807-0310-psoc-27-01-00047.pdf.

Silva, A. (2010). O caminho da terra: revisitando a história do MST no pontal do Paranapanema - SP - desde uma ótica psicopolítica. Psicologia em Estudo, 15(1), 137-149. Recuperado de http://www.scielo.br/pdf/pe/v15n1/a15v15n1.pdf.

Silva, A. (2013). Metas da ação coletiva e vontade de atuar e maneira coletiva na produção da consciência política de agricultores acampados do MST - Brasil. Acta colombiana de Psicología 16(1), 67-79. Recuperado de http:/ /www.scielo.org.co/pdf/acp/v16n1/v16n1 a07.pdf.

Silva, J. G. (1981). O que é questão agrária. Coleção primeiros passos: Brasiliense.

Silva, J. G., \& Del Grossi, M. E. (2000). O novo rural brasileiro. In IAPAR (Org.). Ocupações rurais não-agrícolas: oficina de atualização temática (pp. 165-173). Londrina: IAPAR.

Stedile, J. P. (2012). A questão agrária no Brasil: programas de reforma agrária 1946-2000. São Paulo: Expressão Popular.

Tarelho, L. C. (1988). Da consciência dos direitos à identidade social: os sem terra de Sumaré. Dissertação de Mestrado, Pontifícia Universidade Católica de São Paulo, São Paulo, Brasil.

Vasquez, G. C. F. (2009). A Psicologia na área rural: os assentamentos da reforma agrária e as mulheres assentadas. Psicologia: Ciência e Profissão, 29(4), 856-867.

Velôso, T. M. G., \& Whitaker, D. C. A. (2013). Memórias sobre um conflito de terra em relatos de história de vida. Fractal, Rev. Psicol., 25(1), 23-40.

Vitale, M. P., \& Grubits, S. (2009). Psicologia e povos indígenas: um estudo preliminar do "estado da arte". Revista Psicologia e Saúde, 1(1), 15-30. 
Ximenes, V. M., \& Gois, C. W. L. (2004). Núcleo de Psicologia Comunitária: práxis libertadora. In II Congresso Brasileiro de Extensão Universitária. Belo Horizonte, Brasil.

Wanderley, M. N. B. (2011). Um saber necessário: os estudos rurais no Brasil. Campinas: Editora da Unicamp.

Yamamoto, O. H. (2012). 50 anos de profissão: responsabilidade social ou Projeto ÉticoPolítico. Psicologia: Ciência e Profissão, 32 (n. esp.), 6-17.

Zimerman, A. (2016). Impactos das transações de terra e a violência contra camponeses na América Latina. In XIX Encontro Nacional de Estudos Populacionais. São Paulo, Brasil.

Recebido em: 23/5/2018

Aprovado em: $30 / 6 / 2020$ 